\title{
Research of Safety Pre-control Management System of Power Plants
}

\author{
Li Xinghua ${ }^{1}$ Wang Suli ${ }^{2}$
}

\author{
Li Xinghua, Shandong University of Science and Technology, Qingdao City, \\ Shandong Province,
}

\begin{abstract}
Carrying out safety Pre-control management can offer the power plants clear understanding and overall evaluation of hazard in the range of their productive activities, so as to avoid the hazard turning into potential safety hazard, and to nip it in the bud. On the basis of comprehensively identifying hazard, LEC is used to evaluate the hazard in this paper. According to the evaluation results, the hazard is managed in different grades. In addition, overall design of the system is provided. Forms including short message are suggested to be used, thus to make early warning for the hazard in the safety production process of power plants.
\end{abstract}

Keywords:Safety pre-control management; Hazard; Early warning

\section{Introduction}

Safety pre-control management theories mainly include identification of hazard, analysis and evaluation of hazard, early warning and control of hazard. Among these, hazard identification is considered as the basis of the whole management system. It is the key of pre-control management to identify the factors that may induce accidents in producing activities. On the basis of comprehensive identification of hazard, analysis and evaluation of hazard are mainly aimed at the possibility of every hazard and the serious degree of consequence.

2. Basic ideas of carrying out safety pre-control management system of hazard in power plants

The nature of safety pre-control management system is to change the post-process into pre-control. The purpose of establishing safety precontrol management system is to nip the unsafe factors and the hidden danger of workplace in the productive process in the bud, thus to restrict the potential losses to the lowest ${ }^{[1]}$. In this way, the original follow-up control will be transferred into pre-control. The main objectives to realize the fundamental transform of management ideas and methods are:

1) To accurately and comprehensively identify the hazard during the production of power plants;

2) To provide scientific quantitative estimation for the range of various safety states of power plants;

3) To accurately forecast the potential developmental tendency of various safety states; to compare the trend value and the range of various safety states; to send out the warning information in time by computational analysis;

4) To implement pre-control countermeasures of warning information; to deal with emergent condition in time, thus to prevent accidents and reduce accident loss;

5) To feed back the pre-control 
countermeasures timely to relevant department and submit the control effects to the information center, and so forth until the productive process is controlled in the safe condition.

\section{To identify the hazard by using the important theory of accident cause structure}

The power sector is an industry with full of potential risks. Combining with the production field of power enterprises, LEC is used to evaluate the risk factor of the production in power plants. LEC, also known as Graham Kinney method, is suitable for the hazard assessment of "operating conditions in the environment of potential risks" [2"]. Firstly, this method is used to evaluate the risks of casualties in the system. It evaluates through the product of index values in three aspects related to systematic hazard rate. Secondly, as a semiquantitative evaluation method, LEC simplifies the evaluation process. According to experience and estimation in the past, the three aspects mentioned above are respectively divided into different grades, then to confirm different values. After that, hazard of the operating conditions will be evaluated by the product $\mathrm{D}$ of the three values.

According to the formula risks $\mathrm{D}=\mathrm{L} \times \mathrm{E} \times \mathrm{C}$

There are three main factors influencing the hazard during production in power plants.

In the formula:D-dangerous level of operating conditions; $\mathrm{L}$ - possibility of accidents and hazard;E- the frequency to be exposed to hazardous environment; $\mathrm{C}$ - consequence and influence might be produced after the accidents.

\section{Design for safety pre-control management system in power plants}

Design for safety pre-control management system in power plants considers VB.net as the main system development software; this system database uses Microsoft SQL Server 2008; the modes of safety pre-control management system in power plants mainly take $\mathrm{B} / \mathrm{S}$ mode into account. The whole safety pre-control management system in power plants can be divided into the following modules.

1) User system management module

This operation module can be divided into foreground and background. In the system, there are user department, teams of each department and username. Passwords are the initial passwords established by the system. In front operational management, there are user registration function and user login function. After registration, normal users can browse and query in all the modules, but they have no rights to save, modify and delete the information; system administrators are responsible for the background operation which provides the functions including password change, modification of user information, configuration of user permission and so on. System roles and the corresponding permission of each role are allocated to every user by the system administrators, thus to effectively protect the system data security.

2)The Management Module of Hazard Sources

The module achieves the management of hazard sources mainly by establishment and application of dangerous source database which is a 
kernel module. The managing content of this module is mainly the hazard sources and their regulatory measures and equipped with functions of scanning, inquiry, entering, update and deletion. The dangerous source database will enter the hazard sources and their regulatory measures into the system in order to make the management of hazard sources more simple and perceptual intuition, hierarchical management for all hazard sources and constantly updating the dangerous source database.

3)The Management Module of Safety Training

The backstage of management module of safety training is equipped with functions of classification and addition of safety knowledge and update. The system administrator will divide safety knowledge into the form of image-text and video, classify and load to the documents and database to achieve the functions of auto-showing (play by subsection or in order) safety knowledge of combining the image-text and video.

\section{4)The Management Module of Endorsement}

The module foreground is equipped with functions of inquiry of breaking rules and regulations and print, according to the type of inquiry, it is can check the relevant content of corresponding files of breaking rules and regulations and print as required. If you need inquire the violation department's all endorsements, you can input the unlawful department in retrieval field that you can get it, and then you indeed achieve the inquiry and analogy of files of breaking rules and regulations. The module backstage is equipped with functions of generation of violation label, edit and print. The violation label includes violation department, task, violation personnel, violation nature, violation date, violation situation and treatment suggestion and finally you should fill in the violation label, elect the hazard sources produced by this task from database. Individual chooses the hazard sources produced by this task and fill out all records and submit to database to store.

5)The Management Module of Safety Pre-warning Information

It conducts early warning for hazard sources in the process of safety production for the power plant by combination of obtained values of this module and quantitative evaluation of hazard sources. Pre-control system achieves early warning by the form of sending SMS and Email to principals. At first, it should define a value within the range of the value, the system is defined as safety stage. Otherwise, the system will send warning to related principals to rectify and reform and then remove a hidden danger. If modification and reform are not completed within the dates or are not conducted, it should send warning to high rise principals till to remove a hidden danger and then the warning cancels.

By statistic results for predisposing sits and categories of hazard sources, the production manager can discriminate the type, type of work, operational type of high frequency of occurrence in certain specific sites that is convenient to make relevant measure of rectify and reform and adjust job specification.

6)The Module of Information Processing and Feedback

The job content in this module is mainly the feedback of information that 
is making decisions by worked information and system, feeding back to the production field and functional department and then feeding back the executive condition of the production field and functional department to information processing system.

\section{Database design}

From achieved goals and demand analysis for the system, this system database designs the following three classes of database tables.
Because this system is applied for inner-enterprise, in order to achieve convenience for management of the enterprise to employees, this system designs user registration that takes the real-name system, contents must be real and effective. The user message table should not only contain the registration information of normal users but also the registration information of system administrators for all levels, as table1.

\subsection{User Message Table}

Table 1 User message table

\begin{tabular}{cccc}
\hline Field Description & Field Type & Field Name & Instruction \\
\hline UserRegistrationID & int & CustomerID & identity column \\
User Name & varchar & Uid & Not null \\
Password & varchar & Pwd & Not null \\
Gender & varchar & Gender & Not null \\
Real Name & varchar & Realname & Not null \\
Occupation & varchar & Career & Not null \\
Address & varchar & Address & Not null \\
Email & varchar & Email & Not null \\
Telephone & varchar & tel & Not null \\
\hline
\end{tabular}

\subsection{Hazard Source Data Table}

According to characteristics of rough and tumble contents and wide

varieties for hazard sources, the system designs the following eight data tables, as table2.

Table 2 Hazard source kinds

\begin{tabular}{|c|c|c|c|c|c|}
\hline $\begin{array}{l}\mathrm{N} \\
\mathrm{o}\end{array}$ & $\begin{array}{l}\text { Table Name } \\
\text { Description }\end{array}$ & Table Name & No. & $\begin{array}{l}\text { Table Name } \\
\text { Description }\end{array}$ & Table Name \\
\hline 1 & $\begin{array}{l}\text { The Part of Power } \\
\text { Transmission }\end{array}$ & Transmission & 6 & $\begin{array}{l}\text { The Part of Scheduling } \\
\text { and Communication }\end{array}$ & Scheduling \\
\hline 2 & $\begin{array}{l}\text { The Part of Power } \\
\text { Transformation }\end{array}$ & Transformation & 7 & $\begin{array}{l}\text { The Part of } \\
\text { Transportation }\end{array}$ & Transportatio \\
\hline 3 & $\begin{array}{l}\text { The Part of Power } \\
\text { Distribution }\end{array}$ & Distribution & 8 & $\begin{array}{l}\text { Other Parts of House } \\
\text { Property and Wood } \\
\text { working and so on }\end{array}$ & House Proper \\
\hline 4 & $\begin{array}{l}\text { The Part of Relay } \\
\text { Protection }\end{array}$ & RelayProtection & & & \\
\hline 5 & $\begin{array}{l}\text { The Part of High } \\
\text { Pressure Oil Work } \\
\text { Testand Instrument } \\
\text { Calibration }\end{array}$ & High Pressure & & & \\
\hline
\end{tabular}


5.3Violation Recording Data Table
According to the filling contents in violation label, it designs violation recording data table, as table 3

Table 3 Violation recording data table

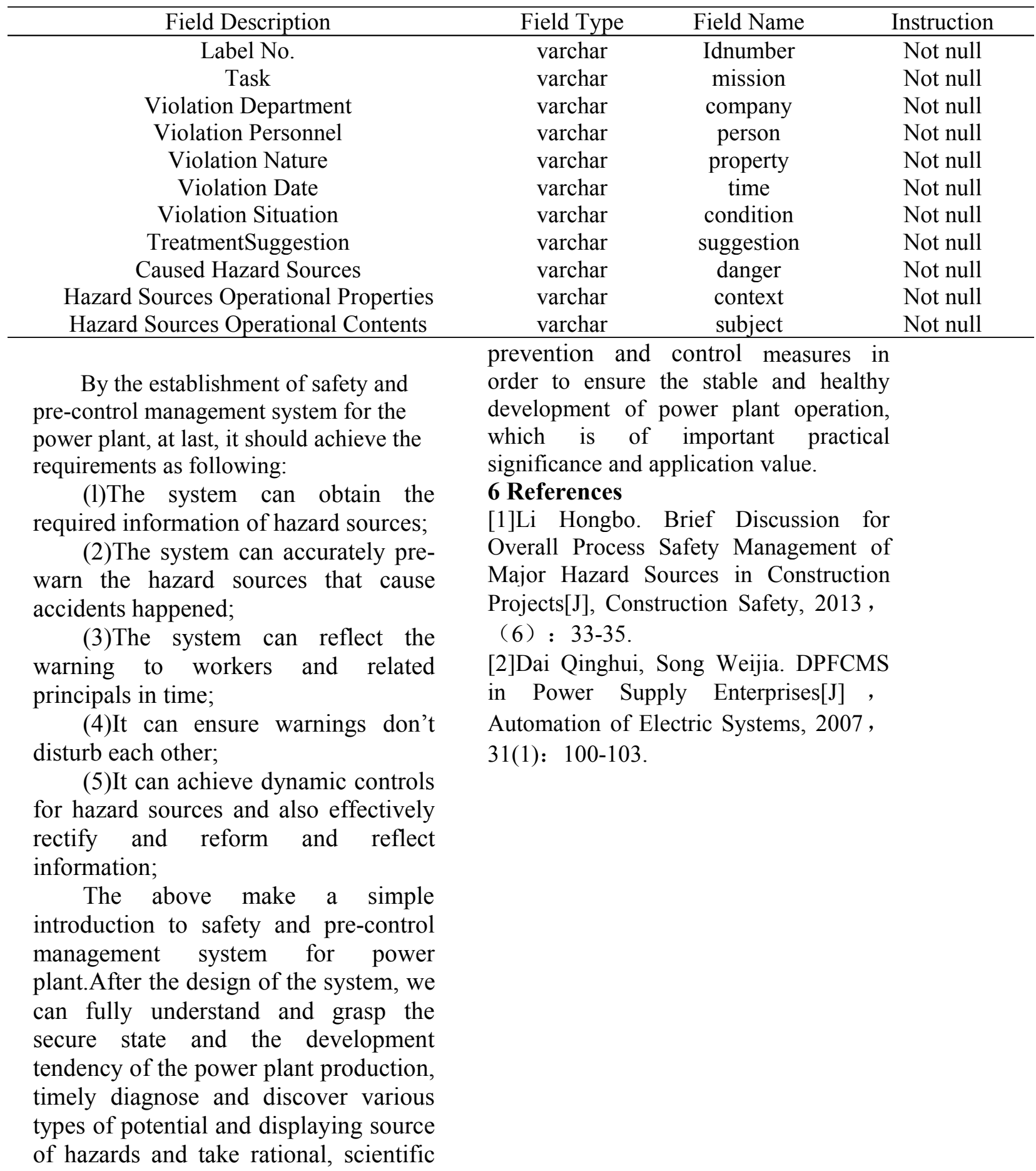

